DOI: $\underline{\text { https://doi.org/10.24867/12GI19Kocic }}$

\title{
UPRAVLJANJE PROIZVODNJOM NAMEŠTAJA UZ PRIMENU SAVREMENOG PRISTUPA POSLOVANJU
}

\section{MANAGEMENT OF FURNITURE PRODUCTION WITH THE APPLICATION OF A MODERN APPROACH TO BUSINESS}

\section{Mila Kocić, Slobodan Morača, Fakultet tehničkih nauka, Novi Sad}

\section{Oblast- PROJEKTNI MENADŽMENT}

Kratak sadržaj - U ovom radu prikazano je upravljanje proizvodnjom nameštaja, zatečeno stanje i predlog unapređenja procesa poslovanja automatizacijom, uz implementaciju ERP sistema, RFID i Clouding tehnologija.

Ključne reči: projektni menadžment, upravljanje proizvodnjom, ERP sistem, RFID sistem, Cloud

\begin{abstract}
The present paper presents the management of furniture production, the current situation and the proposal to improve the business process by automation, with implementing ERP systems, RFID and Clouding technologies.
\end{abstract}

Keywords: production management, project management, ERP system, RFID system, Clouding

\section{UVOD}

Iz kompleksnosti projektnog prilaza proizilazi činjenica da kvalitetan projekat treba da sadrži kombinaciju 3 elementa: pažljivo struktuiran menadžment tim, dobru poslovnu ideju i tržište koje iziskuje realizaciju projekta kojom bi se rešio postojeći problem ili zadovoljila određena potreba.

Predmet istraživanja $u$ ovom radu jeste unapređenje procesa proizvodnje nameštaja uz primenu savremenog kocepta upravljanja, uz predlog usvajanja višeg stepena automatizacije procesa u preduzeću. Osnovni cilj master rada odnosi se na utvrđivanje opravdanosti projekta proizvodnje nameštaja za dnevni boravak uz uvođenje savremenih pristupa poslovanju. Ukoliko se analizom dokaže opravdanost, pristupa se pokretanju postupka za izdavanje odobrenja za realizaciju projekta.

\section{TEORIJSKE OSNOVE IZ OBLASTI UPRAVLJANJA PROJEKTIMA}

Projekat je privremeni napor preduzet da bi se proizveo jedinstveni proizvod, usluga ili drugi rezultat [1].

\section{NAPOMENA:}

Ovaj rad proistekao je iz master rada čiji mentor je bio dr Slobodan Morača, vanr. prof.
Privremeni napor označava da svaki projekat ima početak i kraj. Kraj predstavlja trenutak kada su definisani ciljevi projekta postignuti, odnosno kada više nije potrebno postojanje projekta. Projekat jeste privremenog karaktera, ali to ne znači da je njegovo trajanje kratko. Veoma često efekti, odnosno rezultati projekta traju dugo- nekoliko godina, decenija, pa i vekova. Sam uticaj projekta na sredinu može da traje mnogo duže nego sam projekat.

Uspešnost projekta ogleda se $\mathrm{u}$ ispunjavanju zahteva interesnih grupa (projektnih stejkholdera), završetku u definisanom roku i nepremašenom budžetu, ispunjenju definisanih ciljeva i zadovoljenju kvaliteta.

Okosnicu životnog ciklusa projekta čine 4 stavke i one su raspoređene po vremenskom odvijanju projekta: iniciranje, pripremene aktivnosti i organizovanje, izvođenje projekta i aktivnosti za završavanje projekta.

Upravljanje projektima se ostvaruje kroz odgovarajuću primenu $\mathrm{i}$ integraciju 42 logički grupisana procesa vođenja procesa, sakupljenih u 5 predmetnih grupa procesa: pokretanje, planiranje, izvršenje, nadzor i kontrola, završavanje [1]

Uspešno upravljanje projektima i primena metodologije, može da dovede do sledećih koristi za organizaciju:

- Brži izlazak na tržište, na osnovu bolje kontrole obima projekta

- Smanjen rizik u okviru celokupnog projekta

- Kvalitetniji proces donošenja odluka

- Veće zadovoljstvo potrošača

- Više vremena za stvaranje nove vrednosti

\section{UPRAVLJANJE PROJEKTNIM TIMOM}

Timski rad se spontano nametnuo kao jedna praktična neophodnost. To se naročito ogleda $u$ rešavanju komplikovanih zadataka i problema jer se pokazalo da su znanje i informisanost na daleko višem nivou u timu nego pojedinačno.

Nijedan tim ne postoji bez zadatka za koji je oformljen. Uspešno formiran tim svojim rezultatima prevazilazi individualne rezultate. Uspešan tim lakše prevazilazi potreškoće nego pojedinac, podstiče se kreativnost među članovima tima, razvija poverenje, jača se komunikacija, podstiče se stalno učenje i usavršavanje, donose se 
kvalitetne poslovne odluke i poboljšava se zadovoljstvo zaposlenih radom.

U današnjim, složenim uslovima promenljive okoline, preduzeća ne mogu bez menadžerskog vođenja da se prilagođavaju promenama i idu napred. Samo strateški orijentisani lideri, koji mogu da predvide buduće događaje i akcije, mogu da navedu ljude da ih slede u ostvarenju predviđenih akcija i promena.

Projektni lider treba da poseduje niz osobina čija kombinacija omogućava ne da on radi bolje od ostalih članova tima, već da motiviše tim da kvalitetnije obavljaju zadatke i od njega samog, poput: kreativnosti, posvećenosti cilju, entuzijazma, sposobnosti dobre procene itd. Pod okriljem dobrog projektnog lidera, članovi tima će svoju energiju, volju i znanje posvetiti dostizanju željenog cilja, i preuzeti odgovornost za postupke.

Raznovrsnost ideja, mišljenja i karaktera u jednom multifunkcionalnom timu se može posmatrati dvojako: kao odlična podloga za iznalaženje rešenja na projektu, ali i veća šansa za pojavu konflikata. Projektni lider mora da prihvati činjenicu da konflikti nisu loši za tim, i mogu da budu konstruktivni, ali i da su neslaganja pojava koja će se permanentno ponavljati. Uz kvalitetno vođenje, ovakve pojave se mogu prevesti u koristi za celokupan projekat tim.

\section{KONCEPT PROJEKTA}

Koncept projekta definiše razlog postojanja projekta i omogućava da projekat bude u saglasnosti sa vizijom, misijom i strategijama organizacija koja učestvuju u izvršenju projekta (sponzori, kontrolne agencije, korisnici, itd). Koncept projekta određuje prilaz u rešavanju problema, kritične puteve, opis projekta i druge bitne informacije značajne za donošenje odluke o prihvatanju projekta i za narednu fazu - planiranje [2].

Važno je konzicno predstaviti ideju projekta, koje benefite imaju stejkholderi njenom realizacijom, i koji su ciljevi. Nakon identifikacije i definisanja ideje, a pre donošenja odluke o pokretanju projekta, potrebno je prikupiti sve informacije i uraditi analize koje su relevantne za sam projekat. Cilj sprovođenja svih navedenih koraka pre donošenja odluke za realizaciju projekta, jeste da se na nedvosmislen i transparentan način prikažu razlozi zašto projekat treba da bude realizovan.

Ideja projekta koja je razmatrana u radu je unapređenje procesa upravljanja proizvodnjom nameštaja kroz implementaciju savremenih IT struktura.

$\mathrm{U}$ fokusu je agilan način proizvodnje koji podrazumeva prilagođavanje načina rada i proizvodnih procesa zahtevima korisnika. Izabrana su dva reprezentativna proizvoda koja su, zbog potrebe povećanja nivoa fleksibilnosti i agilnosti u radu, projektovana da budu modularnog tipa. Modularnost proizvoda olakšava ispunjenje zahteva i potreba korisnika, ali otežava procese automatizacije i primene konvencionalnih IT rešenja. Agilnost i fleksibilost omogućavaju da se na tržište izbacuje modularni proizvod u nekom svom osnovnom obliku, brzo istestira i na osnovu povratnih informacija dorađuje, zatim ponovo testira na tržištu i tako u cikličnim procesima dođe do konačnog proizvoda koji zaista odgovara tržištu. Agilna metodologija se najčešće koristi za proizvodnju onih proizvoda za koje ne znamo tačno kako će na kraju da izgledaju, odnosno ne znamo šta će korisnici odabrati. Zajedno sa klijentom, kroz mnogobrojne interakcije, proizvod se prilagođava dok ne dođemo do konačnog izgleda. U našem slučaju, iako su u pitanju samo 2 proizvoda iz čitavog proizvodnog asortimana, oni mogu kako modularnošću, tako i kombinacijama boja štofa da odgovore većini zahteva.

Primenom savremenih IT rešenje omogućava se aktivno uključenje korisnika tokom procesa pripreme za proizvodnju, ali i realizacija procesa proizvodnje, skladištenja, distribucije itd. Krajnji kupac može da prilagođava i menja opcije garniture u zavisnosti od trenutnih potreba i karakteristika sopstvenog prostora.

\section{SISTEM BEZBEDNOSTI I ZDRAVLJA NA RADU}

Poseban izazov svakog procesa proizvodnje je upravljanje sistemom zaštite na radu. Elementi savremenih IT sistema, u okviru podrške upravljanja proizvodnjom, bi morali da integrišu dati aspekt. Od procesa identifikacije i procene rizika, pa sve do generisanja mehanizama i mera za sprečavanje neželjenih pojava ili snižavanja nivoa rizika tokom procesa proizvodnje. Svaki proce proizvodnje generiše značajan broj rizika, što je posebno primetno u proizvodnji nameštaja. Savremene IT strukture, pored ostalog, bi imale zadatak da omoguće pristup informacijama o potencijalnim opasnostima i štetnostima na radnom mestu, ali i da generišu trigere $i$ niz drugih zaštitnih naprava i mehanizama, kojima bi se onemogućilo narušavanje bezbednosnih mera. Takvi mehanizmi bi mogli da prekidaju rad mašina usled nebezbednog stanja ili da sprečavaju pristup opasnim zonama. Pored navedenog, IT sistem bi imao evidencije o zaposlenim, njihovim mogućnostima i ograničenjima, praktičnoj osposobljenosti za obavljanje poslova itd.

Sistem bezbednosti i zdravlja na radu zasniva se na primeni principa prevencije od eventualnih povreda tokom rada zaposlenih, kao i nastanka oboljenja ili narušavanja zdravlja zaposlenih. Osnova procene rizika od navedenog je utvrđivanje postojanja i nivoa opasnosti i štetnosti na svakom radnom mestu i u radnom okruženju koje mogu da prouzrokuju eventualne povrede na radu i profesionalna oboljenja, kao i procenat verovatnoće nastanka istih.

Dokumentovanjem procene rizika u preduzeću će se omogućiti da poslodavac sagleda ukupno stanje uslova rada u preduzeću, ali ima i pregledno sačinjene mere i prioritete otklanjanja rizika ili minimiziranja istog. Najveći benefit postojanja ovakvog dokumenta je što poslodavac u svakom trenutku ima uvid $u$ stanje bezbednosti i zdravlja na radu, stepena implementacije propisanih mera,a u svrhu bezbednog i zdravog rada svih zaposlenih u preduzeću.

\section{PROCES PROIZVODNJE}

Proizvodni proces predstavlja skup međusobno povezanih aktivnosti preko kojih se vrši povećanje vrednosti 
polaznih materijala. Drugim rečima, proizvodni proces predstavlja skup aktivnosti, preko kojih se vrši transformacija poluproizvoda ili sirovina $u$ gotove proizvode. Proizvodni proces se sastoji iz jednog ili više tehnoloških procesa, a odvija se u proizvodnom sistemu. U proizvodnom procesu se vrši transformacija sirovina poluproizvoda u gotove proizvode. Međutim, proizvodni proces obuhvata, osim transformacije i aktivnosti koje se odnose na definisanje proizvoda, konstrukciju i proračun elemenata proizvoda, organizaciju proizvodnje, pripremu sredstava za proizvodnju, etapno Oblikovanje i obradu detalja i dr [4].

\subsection{Savremeni koncept upravljanja proizvodnjom}

Značaj upravljanja proizvodnjom i njen uticaj na rezultate poslovanja je u stalnom porastu razvojem tehnologije i povećanjem stepena automatizacije $u$ proizvodnim pogonima.

Čovek je oduvek imao ograničene sposobnosti percepcije i reagovanja na situacije u okolini. Kako bi bio što spremniji na situacije koje slede ili pak kontrolisati i nadgledati postojeće - potrebna mu je podrška. Neophodnost uvođenja veštačke inteligencije $u$ savremenom svetu postaje neophodnost.

Veštačka inteligencija može da „odmeni“ čoveka, obavljajući za njega poslove koji zahtevaju: ponavljanje, mašinsku preciznost, ujednačen stepen kvaliteta, kontrolu $\mathrm{i}$ visok stepen rizika. Uslovi u kojima se odvija proizvodnja postaju humaniji, a tehničko-tehnološki uslovi postaju napredniji pa tako sada veštačka inteligencija omogućava da čovek radi u poboljšanim uislovima, a da mašina obavlja posao za koji je do skoro obično radniku bilo potrebno duže vremena, snage ili veština.

Jačanje održivosti i konkurentnosti proizvođača proizvoda od drveta sa visokom dodatom vrednošću, a posebno nameštaja, postići će se pre svega kroz kontinuirano unapređenje osnovnih poslovnih funkcija (organizacija rada, unapređenje procesa nabavke, upravljanje troškovima, planiranje i upravljanje prodajom i istraživanje tržišta, merenje učinka zaposlenih i poslovno planiranje). To je prvi uslov za ostvarenje održivog plasmana nameštaja od drveta na globalna tržišta. Uvažavajući važnost i značaj spoljašnjih faktora za poboljšanje konkurentske pozicije proizvođača nameštaja od drveta, ovim kompanijama je pre svega neophodno jačanje sopstvenih kapaciteta, poslovnih i stručnih veština, kako bi na najefikasniji način iskoristile podsticajne mere podrške za olakšanje pristupa novim tržištima[4].

\subsection{Problemi i izazovi sa kojima se preduzeće trenutno susreće}

Operativni poslovi oduzimaju previše vremena radnicima. Zaposleni se susreću sa obimnom papirologijom koju treba da preuzmu, popune i predaju. Većina tih aktivnosti se obavlja ručno. Izveštaji se šalju jednom dnevno. Produktivnost opada ili stagnira jer se zaposleni na svakodnevnom ili pak nedeljnom nivou suočavaju sa dvostrukim unosom podataka, greškama prilikom popunjavanja izveštaja, itd. Kako preduzeće raste, procesi se usložnjavaju. Zaposleni rade u programima koji nisu međusobno povezani, informacije kasne ili se uopšte ne prosleđuju.

Zaposleni određene evidencije vode u Excel tabelama. Menadžment ne može da integriše podatke iz različitih izvora. To u velikoj meri komplikuje dalje analize, ali i donošenje poslovnih odluka. Zaposleni rade prekovremeno jer u toku radne smene ne mogu da postignu sav posao koji je planiran za taj dan.

Uložen je veliki kapital u mašine, kadar je kvalitetno obučen. Međutim, dolazi do zastoja - neke mašine i radna mesta su preopterećeni, stvaraju se "uska grla", neke mašine ne rade punim kapacitetom. Ne postoji planiranje iskorišćenosti kapaciteta na osnovu trendova iz prošlosti (dnevni, nedelji, mesečni, kvartalni i godišnji nivo) ili na osnovu primljenih porudžbina sa rokovima isporuke. Menadžment nema precizan podatak koje sirovine je potrebno poručiti u datom trenutku jer se materijal troši konstantno.

\subsection{ERP sistem}

Dobra poslovna ideja i kvalitetno urađen biznis model predstavljaju osnov za razvoj profitabilnosti i produktivnosti. Međutim, kako bi se sistem razvijao i bio održiv, neophodno je da postoji adekvatna evidencija, kontrola i koordinacija svih aktivnosti preduzeća. Poslovni dokumenti koji su vešto kontrolisani, transparentni i koji evidentiraju nastale promene su osnova poslovanja.

ERP (Enterprise Resource Planning) predstavlja poslovni softver namenjen integraciji poslovnih procesa $\mathrm{u}$ jednu celinu. Obezbeđuje pomoć menadžmentu u odlučivanju, ali i kvalitetnijem upravljanju resursima.

Poslovanje koje se zasniva na korišćenju pojedinačnih softverskih rešenja koja obrađuju pojedine poslovne procese - knjigovodstvo, kupci, stanje robe, postaje zastarelo i kompanije sve više teže da sve procese ujedine u jedinstveni sistem koji će im omogućiti da na jednom mestu, u jednoj aplikaciji, na jednostavan način prate promene, unose ulazne podatke, ali i imaju na raspolaganju celokupnu bazu podataka - izveštaje i analize vezane za prodaju, marketing, kupce i dobavljače, knjigovodstvo, logistiku, ljudske resurse.

ERP omogućava standardizaciju procesa na nivou celog preduzeća, uz optimizaciju poslovnih procesa, što može da olakša postizanje punog potencijala poslovanja. Informacije se nalaze na jednom mestu, što omogućava menadžementu fleksibilnost u praćenju stalnih promena $\mathrm{u}$ sferi tržišta, standarda i regulative i planiranje u skladu sa tim.

\subsection{RFID sistem}

RFID - Radio Frequency Identification (eng.) je tehnologija automatske identifikacije uz pomoć radio talasa.

RFID tehnologija integrisana za izvršnim proizvodnim informacionim sistemom i ERP sistemom se može koristiti u obezbeđivanju transparentnosti ulaznih sirovina, nedovršene proizvodnje, terminiranju radnih naloga, skladištenju i otpremi gotovih proizvoda 
potrošačima. Omogućava praćenje sledljivosti proizvoda, koja podrazumeva saznanje koji operateri i koji meterijali su upotrebljeni u izradi datog proizvoda, odnosno radnog naloga [6].

Primenom RFID tehnologije, preduzeće ima mogućnost uvida i rešavanja problema $\mathrm{i} / \mathrm{ili}$ nedostataka na relaciji proizvodni-poslovni procesi, čime se povećava kvalitet, produktivnost, efikasnost i stepen iskorišćenja resursa.

Tri osnovne komponente RFID sistema su:

1. transponder

2. čitač

3. kontroler

Neophodna je veza između RFID čitača i računarskog sistema, koji je lokacija skladištenja i ažuriranja prikupljenih podataka. Ova veza se uspostavlja pomoću middleware platforme koja je spona između RFID čitača i ERP informacionog sistema.

\subsection{Cloud tehnologija}

Automatizacijom procesa na nivou preduzeća uvođenjem ERP sistema i RFID tehnologije, zaposleni u preduzeću mogu da urade više posla za manje vremena. Mašine su dobre za repetitivne zadatke.

Međutim, uvođenjem ERP sistema i RFID tehnologije, neke aktivnosti u preduzeću još uvek nisu dobro organizovane. Naime, komunikacija među zaposlenima i čuvanje podataka van informacionog sistema su kritične tačke.

Cloud tehnologija obezbeđuje korisnicima da uz manje uloženih sredstava dobiju istu ili veću vrednost.

Jedna od platformi koja se izdvaja jeste Google Workspace (pređašnji Google Gsuite). Ova platforma omogućava zaposlenima korišćenje alata za kolaboraciju. Integrisane aplikacije omogućavaju zaposlenima da korespondiraju putem mejla, obavljaju video pozive, prave virtualne timove, ažuriraju kalendar rokova i bitnih događaja, postavljaju fajlove i dele ih sa kolegama, itd.

\section{IMPLEMENTACIJA}

Za kvalitetno praćenje tokova u poslovanju preduzeća neophodan je kvalitetan softverski sistem koji integriše sve procese u poslovanju i olakšava upravljanje svim poslovnim procesima, dokumentacijom koja ih prati, kao i ljudskim resursima i promenama koje su neminovnost.

Integrisani poslovni sistem omogućava širi spektar praćenja poslovnih promena i omogućava donošenje odluka u pravo vreme. Svaku promenu tokom procesa pripreme $\mathrm{i}$ realizacije proizvodnje treba da prati dokumentacija (u digitalnom ili papirnom obliku) u kojoj su opisani osnovni parametri koji karakterišu datu promenu. Identifikovana stanja i promene se ažuriraju, a podaci se koriste za detaljne analize i izveštaje.

Integrisani poslovni sistem prati i poštuje sve tokove poslovanja, pri čemu je od velike važnosti koji se podaci $i$ u kom obliku čuvaju u bazu podataka.

\subsection{Finansijska analiza}

Detaljan pregled svih predviđenih troškova može da pruži uvid gde se može uštedeti, ali i gde su ključni problemi. Procenom minimalnog nivoa svakog pojedinačnog troška, menadžer može da izvrši analizu kolika odstupanja od navedenog preduzeće može finansijski da izdrži.

Važno je uračunati i dodatne troškove za fond rezerve, tj. za slučaj da projekat traje nešto duže nego što je planirano. Kombinacijom procenjenih troškova, procenjenih prihoda, realnih, nepredviđenih okolnosti i pretpostavki, dobija se realna investiciona potreba.

\section{ZAKLJUČAK}

Integrisani poslovni sistem, kao osnovni pravac unapređenja procesa proizvodnje, omogućava širok spektar praćenja poslovnih promena. U okviru projekta unapređenja od velike važnosti je omogućavanje prikupljanja, oblikovanja $\mathrm{i}$ analize podataka iz procesa.

Ako su ljudi najznačajniji resurs, preduzeće treba olakšati njihov posao kroz digitalizaciju, standardizacija i automatizaciju procesa. $\mathrm{Na}$ taj način bi se skratilo vreme realizacije procesa i povećao nivo kvaliteta.

\section{LITERATURA}

[1] Grupa prevodilaca: B. Lalić, U. Marjanović, D. Miražić, Vodič kroz korpus znanja za upravljanje projektima (PMBOK vodič), 4. izdanje, Fakultet tehničkih nauka Novi Sad, 2010.

[2] N. Radaković, Menadžment projekata - materijal za nastavu, Fakultet tehničkih nauka Novi Sad, 2008 .

[3] P. Jovanović, Upravljanje projektom, Visoka škola za projektni menadžment, Beograd, 2010.

[4] D. Skakić, A. Krdžović, Finalna prerada drveta, Šumarski fakultet, Beograd, 1996.

[5] http://www.europeanprogres.org/dokumenti/48 186782 akcioni-plan-podrske-drvnoj-industrijisrbije.pdf

[6] Z. Tešić, S. Morača, Primena RFID tehnologije u upravljanju proizvodnim procesima, Fakultet tehničkih nauka, Novi Sad (INFOTEH-

JAHORINA Vol. 6, Ref. C-5, p. 148-150), 2007.

\section{Kratka biografija}

Mila Kocić, rođena je 5. maja 1988. godine u Novom Sadu, Republika Srbija. Završila je Gimnaziju "Svetozar Marković" u Novom Sadu 2007. godine. Nakon završene gimnazije, upisuje Fakultet tehničkih nauka, smer Industrijsko inženjerstvo i menadžment. Tokom studija ispoljava interesovanja iz oblasti projektnog menadžmenta i liderstva, te 2012. godine brani diplomski rad na temu "Liderstvo u projektnim timovima". Nakon završenih osnovnih akademskih studija, zapošljava se u jednom novosadskom preduzeću i uporedo upisuje master studije na matičnom fakultetu, smer Inženjerski menadžment, usmerenje Projektni menadžment. Oblasti interesovanja i profesionalne preferencije su na polju digitalnog marketinga $\mathrm{i}$ strateškog menadžmenta. 